Ann. rheum. Dis. (1963), 22, 19.

\title{
SYPHILITIC ARTHRITIS
}

\section{DIAGNOSTIC PROBLEMS WITH SPECIAL REFERENCE TO CONGENITAL SYPHILIS}

\author{
BY \\ M. SCOTT GRAY AND T. PHILP \\ The Royal Infirmary, Edinburgh
}

Many clinics are now reporting a fresh increase in the number of patients (mainly males) with infectious syphilis. The rheumatism clinics may be the first to see those cases in which syphilitic disease has attacked the bones or joints of small infants, older children, teenagers, and adults. Because early infectious syphilis was extremely prevalent during and immediately after the second world war, patients who were then missed, or who were inadequately treated, may now be at the stage when gummatous lesions are to be anticipated. Such people may also be the parents of congenital syphilitic offspring.

The joints may be involved at most stages of congenital and acquired syphilis. It is a protean condition, and may appear in many transitional forms between the various clinical types.

In congenital syphilis, arthritis occurs in two forms, and a third form is common to both the congenital and the acquired disease. In infants the typical form is Parrot's syphilitic osteochondritis, whilst in older children "Clutton's joints" are the common manifestation (Clutton, 1886). Certain other forms are analogous to the signs of tertiary syphilis seen in adult cases of acquired syphilis.

D'Arcy Power (1908) classified congenital syphilitic arthritis as follows:

(i) Suppurative arthritis;

(ii) Hydrarthrosis;

(iii) Symmetrical serous synovitis; Clutton's joints;

(iv) Gummatous synovitis;

(v) Chondro-arthritis; ulcerating or von Gie joints.

Axhausen (1914) described two forms of tertiary syphilitic arthritis: synovial and osseous. The synovial form occurs mainly in children. The presence of a painless or painful effusion after trauma may lead to an erroneous diagnosis of tuberculosis. Though called "synovial", it is strictly speaking, a perisynovitis. In exceptional cases a fungous type of arthritis is present. The osseous form occurring in young patients may be primarily an epiphysitis; the articular surface becomes eroded and irregular, and there may be cavitation in the interior of the bone, together with bony outgrowths and a secondary eruption of the inflammatory process into the joint. Although the condition is defined as osseous, all the structures forming the joint are usually affected. In adults the whole of one large joint may be affected, the changes being of an osteo-arthritic nature.

Radiology of Clutton's joints shows effusion without bone involvement; the absence of bone involvement is a feature of gummatous synovitis, though the patient's complaints of pain may lead to the radiological demonstration of disuse osteoporosis. The symmetrical involvement of both knee joints favours a diagnosis of syphilis.

Involvement of articular cartilage may be recognized radiologically by diminution in joint space and, as in the case of the von Gie joint, bone erosion may appear within the involved joint. These erosions are usually well demarcated and occur towards the central areas of the joint. Marginal erosions, such as those seen in tuberculosis, have not yet been observed in congenital syphilitic arthritis.

Besides tuberculosis, other conditions to be considered in the radiological diagnosis include rheumatoid arthritis, osteochondritis dissecans, and, if the condition is unilateral, synovioma.

\section{Case Reports}

The three following case histories illustrate some of these findings.

Case 1, a girl aged 10 years.

Family History.-This girl's mother had a typical obstetric history of repeated abortions before the birth of a full-time viable infant. She was found to have 
a strongly positive Wassermann reaction and associated mental symptoms. She refused treatment and later obstructed her daughter's out-patient attendances.

Clinical History.-A diagnosis of tuberculous interstitial keratitis had been made in 1950 when the child was 8 years old. After an injury to her right knee 5 months later, she developed a tenosynovitis of that joint, and within the next 2 months both knees became swollen and painful. A painless effusion then developed in the left ankle. Despite the usual conservative treatment for a tuberculous infection, the joints and general condition deteriorated. Special investigations had by now ruled out a tuberculous aetiology; the patient was referred for a second opinion and it was discovered in 1952 that she had congenital syphilitis.

Examination.- She showed marked frontal bossing, bilateral corneal scarring, and typical notching of the incisor teeth. The right knee was swollen and movement was limited, but pain was minimal. The calf

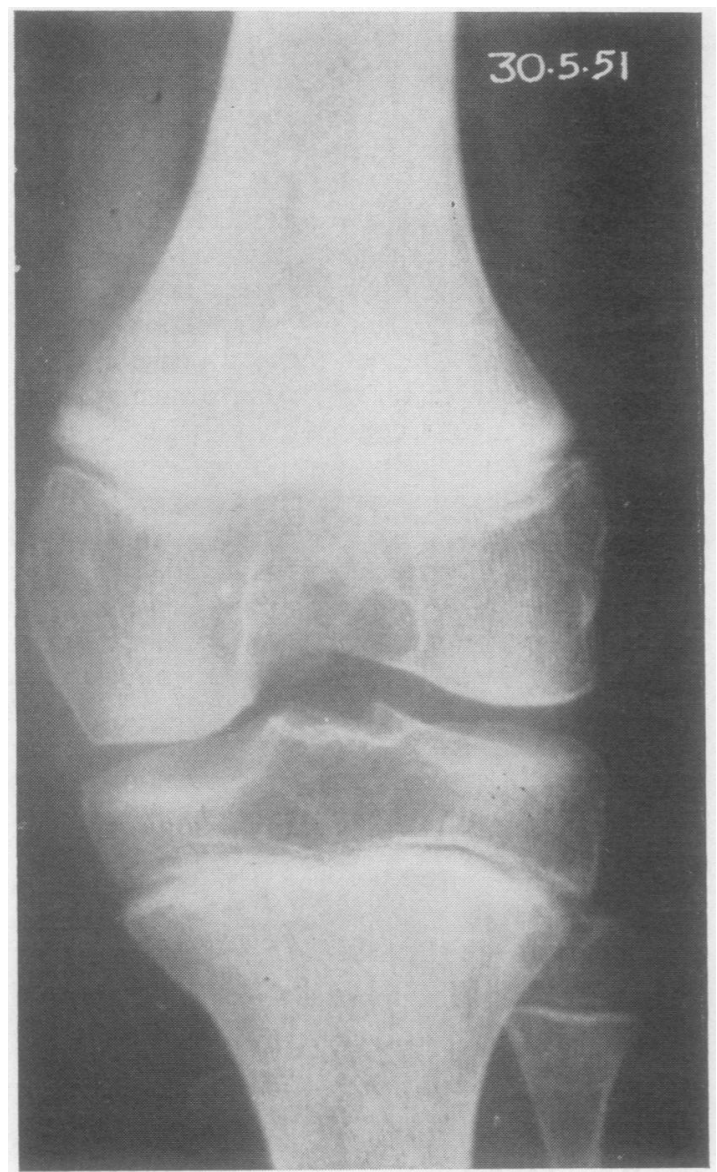

Fig. 1a.-Case 1. Subchondral erosions of left lateral femoral condyle and head of left fibula. Bands of bismuth deposition are seen in the metaphyseal areas. and thigh muscles were atrophied. The left knee and ankle were swollen and painful, movement was limited, and a sabre-blade tibia was present.

All other systems appeared to be normal. The blood Wassermann reaction was strongly positive, but the cerebrospinal fluid was negative.

Treatment.-The combination of penicillin with arsenic and bismuth was the usual treatment for syphilis in Great Britain at that date, and during 4 months in hospital she received 47 mega-units crystalline penicillin, $1 \cdot 25 \mathrm{~g}$. neo-arsphenamine, and $1.5 \mathrm{~g}$. bismuth. In addition, she had local therapy to the joints. Her subsequent out-patient attendance was very erratic, but she received a total of 90 mega-units penicillin, $3.8 \mathrm{~g}$. neo-arsphenamine, and $5 \mathrm{~g}$. bismuth.

The Wassermann reaction remained strongly positive for 3 years, but the titre fell from 32 to 8 dilutions. In the fourth year the reaction reverted to negative and has since remained so.

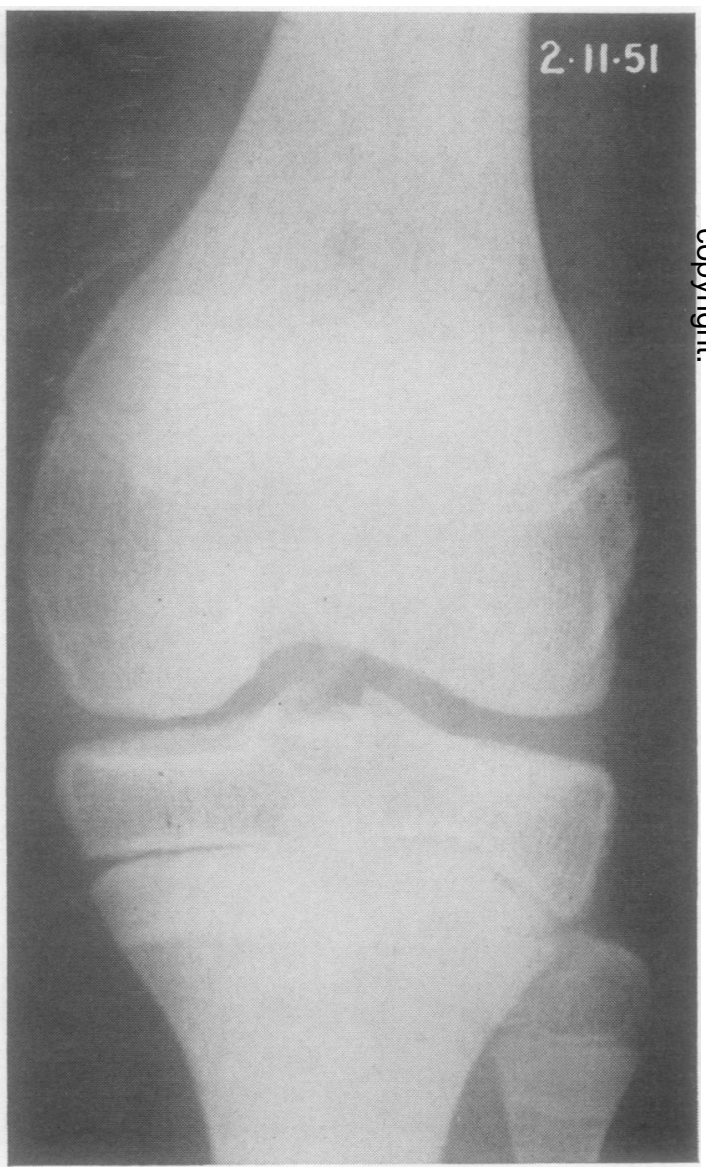

Fig. 1b.-Case 1. Appearances in left knee joint have reverted to normal after 6 months. Bismuth bands now broader. 
Radiology.-A year before admission, no abnormality had been detected in the knee joints, but on admission there was evidence of effusion and synovial thickening within the right knee joint, with no bone changes. Similar but less marked changes were present in the left knee and ankle joints, with slight loss of joint space in the ankle suggesting erosion of the articular cartilage. 3 months later the changes in the left knee joint had progressed to subchondral erosion in the medial aspect of the lateral femoral condyle with preservation of the

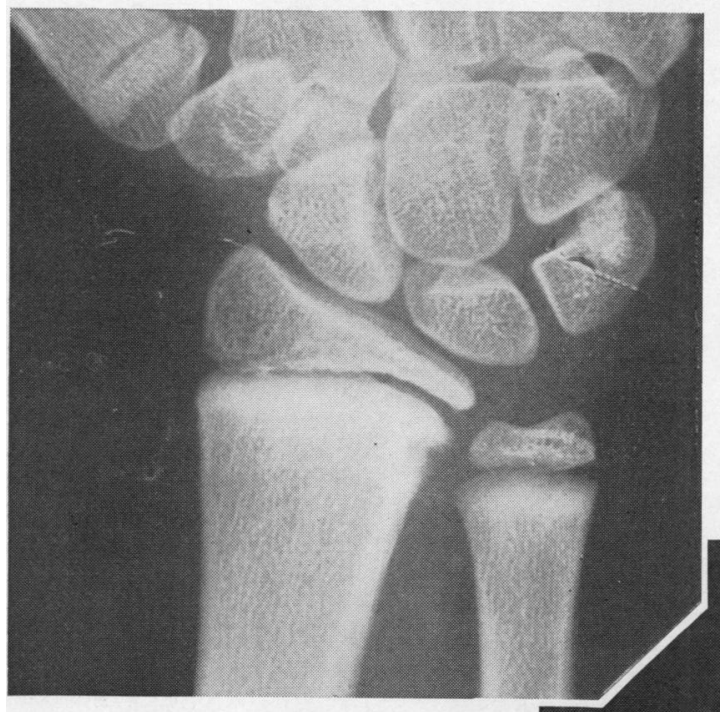

normal joint space, but there was no further deterioration in the other affected joints (Fig. 1a). Some erosion was also noted in the head of the left fibula in relation to the superior tibio-fibular joint. One month later an early erosion was noted at the lower end of the right radius in relation to the inferior radio-ulnar joint (Fig. 2).

These changes were interpreted as being consistent with a syphilitic gummatous arthritis (von Gie).

By this time the effect of the bismuth treatment was showing in the growing ends of the bones, and bands of bismuth deposition were demonstrated in the metaphyseal areas of the knees, wrists, ankles, etc. (Figs 1 and 2).

With further anti-syphilitic treatment the arthritic changes gradually receded and the appearances reverted to normal within the next 6 months (Fig. $1 b$ ).

The bismuth bands became progressively broader and at the final examination in 1954,18 months after she was first seen, there was evidence of an adult type of bismuth distribution, i.e. a generalized increase in density of the whole skeleton (Fig. 3).

Follow-up.-The patient's general health improved so that she was able to dance and play games. She was last seen when aged 16 years, and during the 5 years of observation had no recurrence of joint or eye symptoms.

Fig. 2.-Case 1. Erosion at lower end of right radius in relation to inferior radio-ulnar joint.

Fig. 3.-Case 1. Generalized increase in skeletal density due to adult type of widespread bismuth deposition.

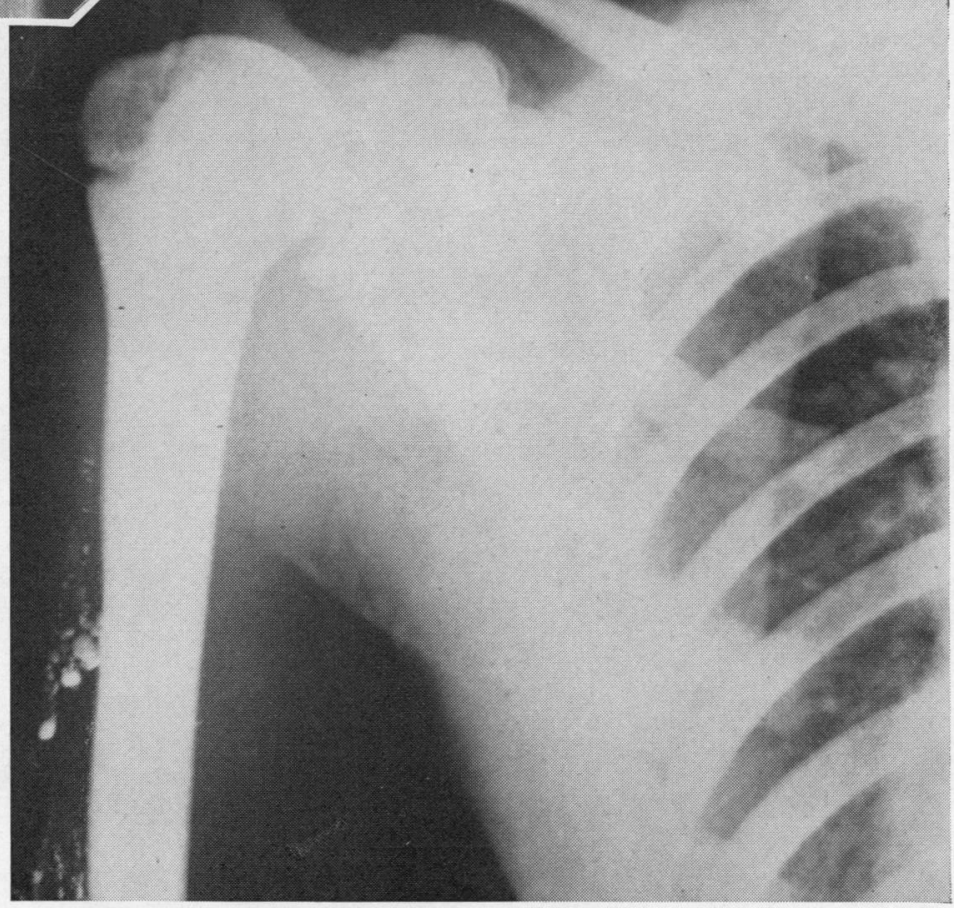


Case 2, a girl aged 17 years.

Family History.-This girl was an illegitimate child, and on examination was found to be a maiden. The mother, who had later married and had two other children, refused treatment, although she had positive blood tests.

Clinical History.-At 9 years of age the patient had developed pain and swelling of both knees and a painless swelling of both ankle joints, with fever, and a tentative diagnosis of rheumatoid arthritis was made. She also developed a transient generalized systolic murmur, but no permanent heart lesion was discovered during the next 4 years, and $x$ rays of the chest and heart were normal. At the age of 12 a bilateral interstitial keratitis developed and relapses were numerous for the next 4 years. After an injury to her right knee, when she was aged 16, a painful swelling developed. There is no record of any treatment for these various symptoms.

Examination.-On her 17th birthday she was admitted to the Royal Blind School, Edinburgh. A routine medical examination now unmasked typical signs of congenital syphilis. There was bilateral corneal scarring, fixed dilated pupils, pale optic discs, and marked choroiditis. She also showed frontal bossing, flattened malar bones, rhagades, typical notched incisors, and deformed molars. All the joints were normal except for a painless swelling of the right knee. Auscultation revealed a presystolic mitral murmur and a non-propagated diastolic aortic murmur. The blood Wassermann reaction was strongly positive, but the cerebrospinal fluid was negative.

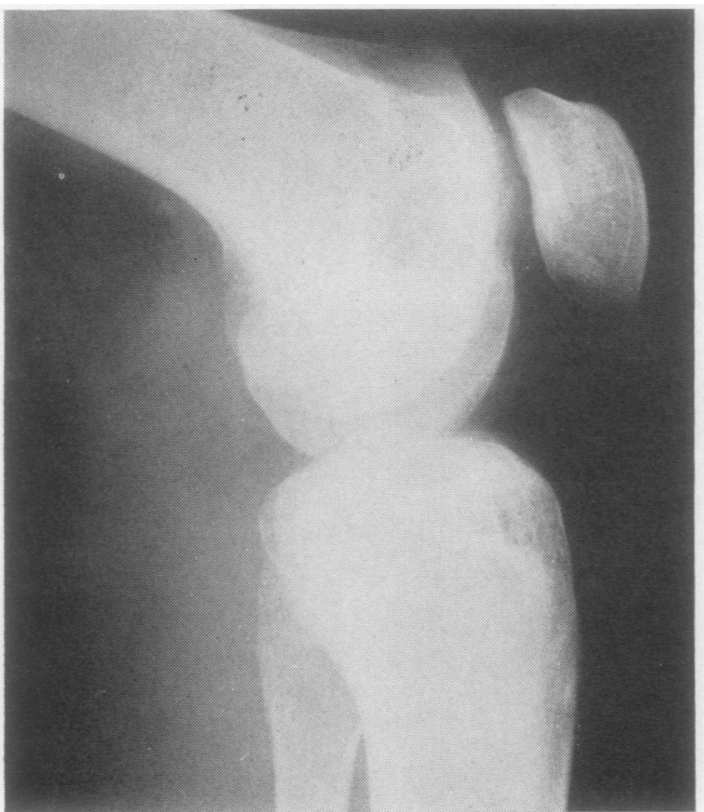

Fig. 4. - Case 2. Lateral views of both knee joints showing bilateral irregularity of articular surfaces with a small loose body in the right anterior joint compartment.

Radiology.-There was slight cardiac enlargement (cardio-thoracic ratio 53 per cent.) with a rather prominent pulmonary artery segment, but no evidence of left atrial enlargement. The ascending portion of the thoracic aorta was also prominent and fine linear calcification could be seen at the root of the aorta in its lateral wall. The lung fields were normal.

Changes in the peripheral joints were confined to the two knees, where there was a symmetrical irregularity of all articular surfaces and a small loose body in the right anterior joint compartment (Fig. 4). There was no evidence of effusion or synovial thickening, but both medial joint spaces were slightly narrowed, suggesting erosion of articular cartilage. The appearances were consistent with an osseous form of gummatous arthritis.

Treatment.- She was admitted to hospital in November, 1955, and within 4 weeks of starting anti-syphilitic treatment with crystalline penicillin, arsenic, and bismuth, she had complete clinical relief of joint symptoms. She remained under treatment until she defaulted in 1957 at 19 years of age, when she had received a total of 26 megaunits crystalline penicillin, $3.5 \mathrm{~g}$. arsenic, and $9 \cdot 5 \mathrm{~g}$. bismuth.

Follow-up.-In 1961, at the age of 24, the patient was traced to a hospital in Rochford, where she had reported with sudden failure of vision and acute onset of deafness. She had now been married for 4 years and had had a normal confinement 2 years previously. The deterioration in vision was due to advanced choroiditis, and nerve deafness was also diagnosed. Radiological examination of the knee joints showed no further deterioration.

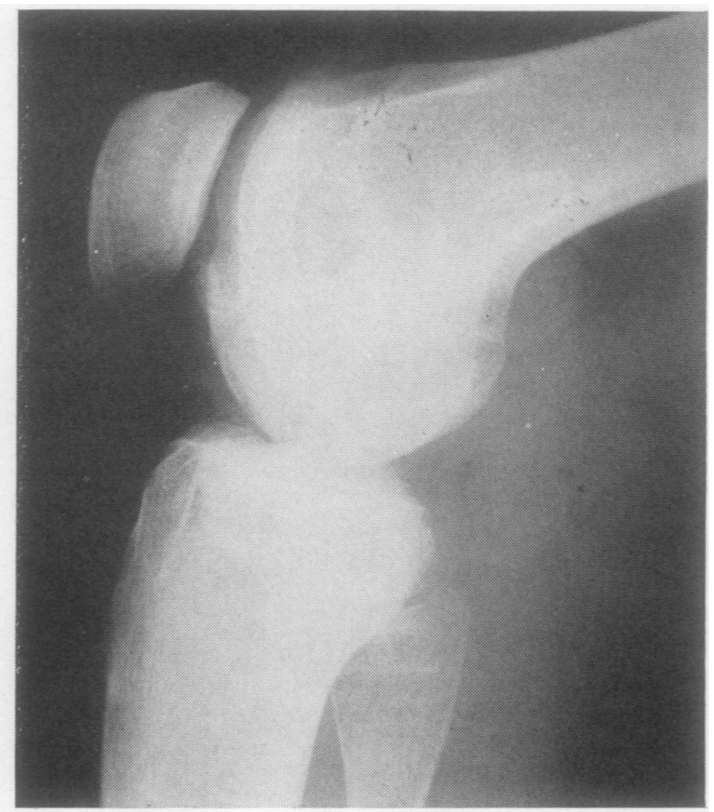


The cardiovascular findings, however, were of particular interest. The pulse now exhibited a well-marked dicrotic notch, the blood pressure was 140/90, and a mitral presystolic and an aortic diastolic murmur propagated down the left border of the sternum were now audible. The apex beat was still palpable in the fifth space in the mid-clavicular line. Radiology showed no evidence of left atrial enlargement, but marked pulsation and prominence of the ascending aorta and early aneurysmal dilatation were seen, and further fine linear calcification had appeared in the wall of the ascending aorta, which was consistent with syphilitic aortitis (Fig. 5).

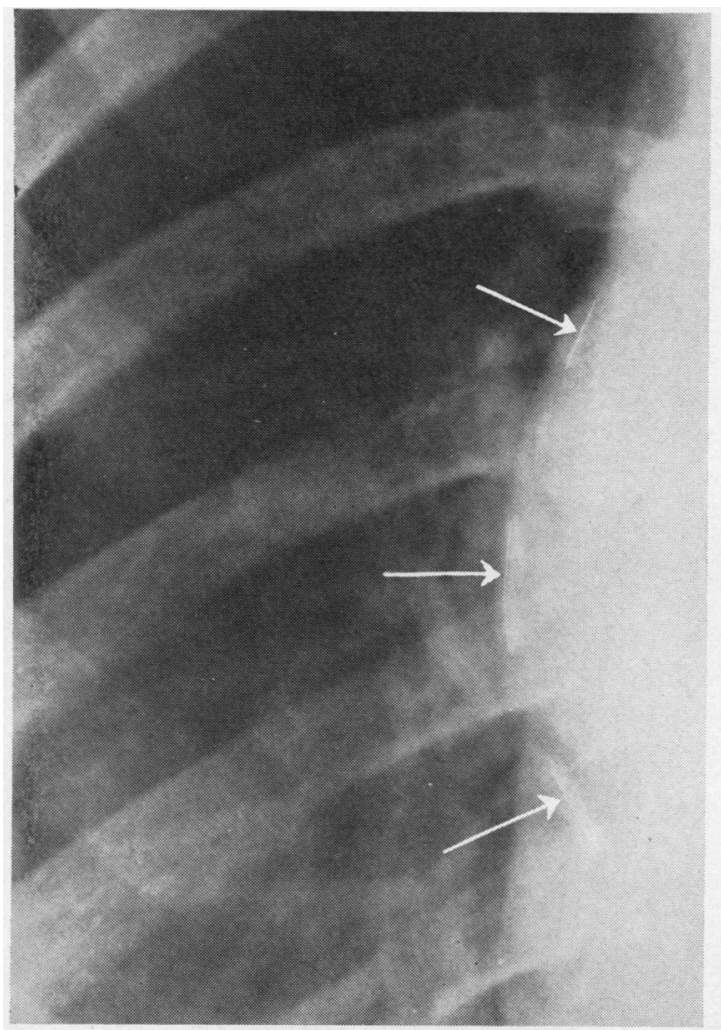

Fig. 5.-Case 2. Fine linear calcification is present in lateral wall of dilated ascending aorta.

The blood Wassermann was recorded as weakly positive, and the cerebrospinal fluid was negative. The patient gave no history of recent joint symptoms, and has now once more disappeared.

\section{Case 3. A married woman aged 31 years.}

Family History.-This patient's parents were dead; her mother had died with a heart condition of unknown cause, and her father had had acquired syphilis. Her brother had been diagnosed as a case of congenital syphilitic osteitis and bilateral interstitial keratitis at the age of 13 years, and had received adequate antisyphilitic treatment.

Examination of the patient's husband was negative. They had no children.

Clinical History. -2 months before admission she had attended the orthopaedic department with painless effusions of both knees present for 8 weeks. With the onset of the joint condition, she had also complained of progressive deafness. She had interstitial keratitis of 5 weeks' duration in the right eye and shortly afterwards the left eye became involved. Radiological examination of the knee joints showed no abnormality, and a diagnosis of tuberculosis was made. There was no earlier history of either eye or joint symptoms. When her general condition began to deteriorate, however, a routine blood Wassermann reaction and Kahn test were found to be strongly positive.

Examination.-She was admitted to hospital in 1951, and further tests excluded the initial diagnosis of tuberculosis.

Radiology.-The knee joints showed well-marked softtissue swelling, particularly on the medial aspect of the right knee joint in the region of the medial collateral ligament, and osteoporosis.

Treatment.-After 6 weeks' anti-syphilitic treatment (with penicillin, arsenic, and bismuth) there was clinical but not radiological improvement, and within 3 months she had a full range of movement in both joints. At this stage she had received 69 mega-units crystalline penicillin, $3.5 \mathrm{~g}$. arsenic, and $2.5 \mathrm{~g}$. bismuth. The absence of the bony sclerosis usually associated with a gummatous osteitis was considered to be due to the early institution of intensive treatment, and the affected knees were regarded as examples of von Gie joints.

Follow-up.-In 1952, 12 months after her admission to hospital, radiological examination showed no evidence of soft-tissue swelling, but there were some residual patchy osteoporosis at the lower end of the right femur and upper end of the right tibia with slight diminution of the joint space. A year later the articular surfaces of this joint were intact with no subchondral erosion, although the joint space remained slightly narrower on the right side.

The joint pathology was, however, a minor problem. Within 18 months of her first seeking treatment, she became "stone deaf" and blind, in spite of heroic efforts to save her vision. The blood Wassermann reactions remained strongly positive for 3 years, but have now remained negative for 5 years.

In 1962 the radiological appearance is that of arthritis following cartilage erosion, especially in the right knee joint. There is no soft-tissue swelling, but early bilateral patello-femoral osteo-arthritis is seen, with narrowing of the lateral joint space in the right knee, slight sclerosis of the opposing surfaces, and slight flattening of the superior surface of the affected tibial condyle. 


\section{Discussion}

In cases of syphilitic arthritis the earlier the condition is recognized and treated, the better the prognosis. In our three cases, radiological examination showed a return to normal in the youngest patient, a static condition in the teenage girl, and a progressive change to osteo-arthritis in the oldest patient. The response to anti-syphilitic treatment proved that the underlying pathology was syphilitic.

It would appear that the correct diagnosis of congenital syphilitic arthritis is still dependent on the following criteria: family history, other clinical and radiological manifestations of congenital syphilis, and therapeutic response to anti-syphilitic drugs.

The local management of the joints is of prime importance. Ankylosis is considered more likely to ensue if the articular cartilage has been destroyed, gross deformity with severe crippling being the endresult. However, a fibrous ankylosis may develop which is a serious handicap to the patient. This type of joint lacks the freedom of movement to prevent trauma and the absolute stability which bony ankylosis confers. The temptation to perform an arthrodesis is fraught with risk of non-union. In the present series no weight-bearing was allowed if articular cartilage damage was considered possible. In the youngest patient (Case 1), the lower limbs were splinted night and day until they began to show clinical improvement, and then the splints were worn only at night-time. Active exercises, including a full range of joint movements were started as soon as possible in order to retain mobility, and within 3 weeks active exercises could be performed without pain. All patients also received a course of general massage and exercises.

Frequently a history of trauma, such as that elicited in one of the cases under review, precedes the onset of joint symptoms, and in such instances the whole condition may well be regarded as due to post-traumatic tuberculosis (as in our Cases 1 and 3) unless the possibility of syphilis is considered (Guyot, 1914). Certain points may assist in the differential diagnosis. There is usually less muscular wasting than in tuberculosis, and pain and restriction of movement may be very slight, even after years of neglect of treatment. Suppuration of the joints is rare. Cases of tuberculosis usually show other complications; it is almost inconceivable that a greatly thickened tuberculous joint could be used for any length of time without splintage or adequate treatment without grave aggravation of the complaint.

The question of a cardiac lesion in Case 2 presented another diagnostic problem. Congenital syphilis was recognized in this patient's 17 th year, and her early medical records showed no history of a rheumatic condition. The occurrence, at the age of 9 years, of both painful and painless joint swellings preceding the development of interstitial keratitis and choroiditis is of significance, and the response to anti-syphilitic treatment was excellent. Cases of combined syphilitic and rheumatic valvular disease have been reported by Plice and Edinburg (1942), and by Lisa, Solomon, and Eckstein (1942), and O'Brien, Smith, and Fisher Keller (1955) described 578 cases of cardiovascular syphilis. In our case, 6 years after the demonstration of a mitral and aortic murmur, the cardiac condition has deteriorated without any subjective symptoms; there is now evidence of marked pulsation and prominence of the ascending aorta and early aneurysmal dilatation, but still no evidence of left atrial enlargement. Aortic calcification of a type consistent with syphilitic aortitis is known to have been present since the patient was 17 years old. There has been no clinical evidence of renal damage, and no cardiac imbalance during pregnancy. The confinement was normal and she was delivered at full term of a healthy child. True Austin Flint murmurs have been generally regarded as uncommon in patients with aortic insufficiency. If the clinical evidence in Case 2 is sufficient for a tentative diagnosis of congenital syphilitic aortitis, it would place her in a younger age group than any previously published example.

The subject of cardiovascular involvement in cases of congenital syphilis is still very debatable. Nicol (1950) stated that "valvular lesions do not occur in congenital syphilitics". Hahn (1941) and Allison (1942) were non-commital. Gjestland (1955) believed that lesions were found only in infantile congenital syphilis. McDonald (1932), Laird (1950), and Bonugli (1961) have all given convincing evidence of cardiac involvement. McDonald (1934) also described two cases with anatomical evidence of rheumatic heart disease in addition to signs of syphilitic aortic pathology.

The three patients under consideration had a strongly positive Wassermann reaction which persisted for 3 years, then quite suddenly reverted to negative, and remained negative or doubtfully positive throughout the observation period. The cerebrospinal fluid has remained negative in all three patients. In addition, the difference in age is clearly related to the response to therapy of the affected joints.

Many venereologists have felt frustrated when, in spite of negative serology and adequate treatment, the syphilitic process has progressed. In two of 
these cases there was a simultaneous deterioration of vision and hearing, in spite of intensive therapy. The oldest patient became totally blind and deaf, and the younger girl reported 6 years after therapy with a sudden deterioration of vision and a new symptom of deafness, though there was no recurrence of the joint symptoms.

\section{Summary}

Three female cases of congenital syphilitic arthritis are described.

Methods of treatment and the possibility of changes in the joint pathology as the result of antibiotic therapy are reviewed. Consideration is given to the general management of the affected joints.

There was deterioration of vision and hearing in two of the reported cases, which in one progressed to blindness and complete deafness, in spite of negative serology and intensive anti-syphilitic treatment.

Congenital syphilitic cardiovascular disease and the differential diagnosis from tuberculous lesions are also discussed.

Our thanks are due to Dr. R. Lees and Dr. M. Murrell of Edinburgh Royal Infirmary for permission to publish the case histories, and to Dr. Sleigh Johnson, The General Hospital, Southend-on-Sea, and Dr. Pebbles, Falkirk Royal Infirmary, for their co-operation in permitting access to relevant medical records.

\section{REFERENCES}

Allison, S. D. (1942). Amer. J. Syph., 26212.

Axhausen, G. (1914). Verhandl. Berl. med. Ges., 1913, 44, Pt. 2, p. 364.

Bonugli, F. S. (1961). Brit. J. vener. Dis., 37, 257.

Clutton, H. H. (1886). Lancet, 1, 391.

D’Arcy Power, H. (1908). Hospital (London), 43, 411.

Gjestland, T. (1955). Acta derm.-venereol. (Stockh.), 35, Suppl. 34, pp. 325, 327.

Guyot, J. (1914). J. Méd. Bordeaux, 85, 364.
Hahn, R. D. (1941). Amer. J. Syph., 25, 200.

Laird, S. M. (1950). (Discussion) Brit. J. vener. Dis., 26, 123.

Lisa, J. R., Solomon, C., and Eckstein, D. (1942). Arch. Path. (Chicago), 33, 37.

McDonald, S., Jr. (1932). Brit. J. vener. Dis., 8, 263. (1934). Ibid., 10, 183.

Nicol, C. S. (1950). (Discussion) Ibid., 10, 183.

O'Brien, J. F., Smith, C. A., and Fisher Keller, M. A. (1955). Ibid., 31, 74.

Plice, S. G., and Edinburg, J. J. (1942). Urol. cutan. Rev., 46, 137.

\section{Arthrite syphilitique}

RÉSUMÉ

On présente des observations de trois femmes atteintes d'arthrite syphilitique congénitale.

On discute les méthodes de traitement et l'idée que la pathologie articulaire peut-être modifiée par la thérapie antibiotique. La thérapie générale des articulations affectées est prise en considération.

Dans deux des cas rapportés on nota une détérioration de la vue et de l'ouie; une de ces femmes devint finalement aveugle et complètement sourde, malgré les réactions sérologiques négatives et un traitement antisyphilitique intensif.

On discute aussi l'atteinte syphilitique cardiovasculaire et le diagnostic différentiel de l'atteinte tuberculeuse et syphilitique des articulations.

\section{Artritis sifilitica}

SUMARIO

Se presentan observaciones de tres mujeres con artritis sifilítica congénita.

Se discuten los métodos de tratamiento así como la posibilidad de alteraciones de la patología articular a consecuencia de la terapia antibiótica. Se toma en consideración la terapia general de las articulaciones afectas.

En dos de los casos relatados se notó un deterioro de la visión y del oído; una de estas mujeres acabó con ceguera y sordera completas, a pesar de la serología negativa y de un tratamiento antisifilítico intensivo.

Se discute también la enfermedad sifilítica cardiovascular y el diagnóstico diferencial de lesiones tuberculosas y sifilíticas de las articulaciones. 